\title{
Antagonism of a PCP Drug Discrimination by Hallucinogens and Related Drugs
}

\author{
William B. West, M.A., Alice Lou, B.S., Kara Pechersky, B.A., Mark E. Chachich, Ph.D.,
} and James B. Appel, Ph.D.

Drugs such as PCP and MK-801 can cause psychotic reactions in humans by antagonizing NMDA receptors. This action is ultimately toxic to certain cortical neurons and may be one mechanism underlying neurodegenerative diseases, including schizophrenia. It has been reported that hallucinogens such as LSD, DOM, and DOI can block the neurotoxic effects of NMDA antagonists, possibly by activating inhibitory 5-HT2A receptors on GABAergic interneurons that normally inhibit glutamatergic projections to the retrosplenial and cingulate cortexes. The purpose of this experiment was to determine the extent to which similar drugs might also alter the behavioral effects of one NMDA antagonist, $P C P$. Rats were trained to discriminate this compound $(2.5 \mathrm{mg} / \mathrm{kg})$ from saline and were then given a series of antagonist tests. It was found that LSD $(0.32 \mathrm{mg} / \mathrm{kg})$ and DOM $(4.0 \mathrm{mg} / \mathrm{kg})$ blocked the PCP cue completely; DMT $(8.0 \mathrm{mg} / \mathrm{kg})$ and a structural congener of LSD, lisuride (LHM; $0.4 \mathrm{mg} / \mathrm{kg}$ ), blocked the effects of PCP partially. The 5-HT/DA antagonists spiperone and ritanserin had no effect on the PCP cue. These data suggest that LSD, DOM, and, less effectively, DMT and LHM can block the behavioral as well as the neurotoxic effects of NMDA antagonists most likely through agonist actions at 5-HT2 receptors.

[Neuropsychopharmacology 22:618-625, 2000] (C) 2000 American College of Neuropsychopharmacology. Published by Elsevier Science Inc.
KEY WORDS: NMDA; Serotonin; LSD; Dopamine; Schizophrenia; Behavior

Phencyclidine (PCP) was synthesized by Parke, Davis \& Company in 1957 and used as an anesthetic under the name Sernyl until the drug was withdrawn in 1965. In normal humans, PCP appeared to induce schizophrenomimetic and other psychotic like effects that persisted long after recovery from anesthesia (Luby et al. 1959). In addition, patients reported changes in body perceptions and seemed to "dissociate" from their normal mental state while remaining conscious (Luby et al. 1959). In hospitalized schizophrenics, PCP reinstated acute, exacerbated psychotic symptoms (Luby et al. 1959, 1962).

From the Behavioral Pharmacology Laboratory, Department of Psychology, University of South Carolina, Columbia, SC.

Address correspondence to: Dr. James B. Appel, Ph.D., Department of Psychology, University of South Carolina, Columbia, SC 29208.

Received July 20, 1999; revised November 18, 1999; accepted December 6, 1999.
Although PCP did not prove to be clinically useful, it generated a wealth of literature, particularly on the relationship between schizophrenia and glutamate. The drug is thought to be bind to a site on the NMDA receptor complex that inhibits excitatory glutamatergic transmission (Lodge and Anis 1982). Indeed, the correlation between reports of psychotic effects and affinity of PCPlike drugs for this site led to the hypothesis that antagonism of the NMDA receptor complex is psychotogenic, if not schizophrenogenic (Javitt and Zukin 1991).

Drug discrimination has been used to study the mechanism of action of PCP and arguably serves as an animal model of the subjective effects of this compound in humans (Koek 1999). Studies using this technique have indicated that there is a strong positive correlation between the potency of ligands that bind to the PCP-binding site on the NMDA receptor complex and ability to substitute for PCP (Koek and Woods 1988). However, the extent to which NMDA antagonists that do not bind to the PCP site may also have psychotomimetic effects is not clear. 
While animal studies have shown that drugs such as CPP (3-[(+/-)-2-carboxypiperazin-4-yl]propyl-1-phosphonic acid) and CGS 19755 (cis-4-phosphonomethyl2-piperidine-carboxylic acid) have PCP-like biochemical and discriminative stimulus effects at high doses (Balster 1991; Koek et al. 1990), clinical trials do not suggest that either of these compounds induce psychotic-like effects (Grotta et al. 1995; Kristensen et al. 1992).

NMDA receptor hypofunction is one mechanism that has been proposed to mediate both the neurotoxic and psychotogenic effects of NMDA antagonists. PCP, MK-801 (dizocilpine), and ketamine have been shown to cause vacuoles in tissue comprised primarily of glutamatergic pyramidal neurons located in the posterior cingulate and retrosplenial cortexes (Olney et al. $1989,1991)$. Of particular relevance to the present research is a report that 5-HT2 agonists such as LSD, DOM, DOI, and DOB (Appel et al. 1982; Branchek et al. 1990; Fiorella et al. 1995a,b; Glennon et al. 1983; KrebsThomson et al. 1998) inhibit the neurotoxic effects of MK-801 (Farber et al. 1998). In addition, ritanserin (a relatively non-selective 5-HT2A/2C and DA antagonist) and SDZ SER-082 (a putatively more selective 5-HT2C antagonist) were given in combination with both DOI and MK-801; ritanserin, but not SDZ SER-082, blocked the neuroprotective effects of DOI. These findings suggest that agonistic action at 5-HT2A receptors might protect against neuronal damage caused by NMDA antagonists (Farber et al. 1998).

The present experiment was designed to examine the extent to which the discriminative stimulus properties of PCP can be antagonized by LSD, DOM, DMT, LHM, ritanserin, and spiperone.

\section{MATERIALS AND METHODS}

\section{Subjects}

Experimentally naïve 90-day old male Sprague-Dawley rats $(n=16)$ weighing approximately $350 \mathrm{~g}$ were purchased from Charles River Breeding Laboratories, Wilmington, MA. They were housed individually in a colony maintained on a $12 \mathrm{~h}$ light-dark schedule (lights on at $0700 \mathrm{~h}$, off at $1900 \mathrm{~h}$ ). Temperature and humidity were held constant at $20-22^{\circ} \mathrm{C}$ and $40-50 \%$, respectively. Initially, animals had free access to both food and water. During this period they were handled at least once a day. Five days before training, water was restricted to one hour per day. Access to water was then restricted to training sessions, weekends (Friday evening to Sunday morning), and a 10-min period following test sessions.

\section{Apparatus}

Eight commercially available experimental chambers (MED Associates ENV 018) housed in light- and sound- attenuating shells (MED Associates ENV 008) were used. Each chamber contained two retractable levers and a dipper that was programmed to deliver $0.1 \mathrm{ml}$ of water for $0.3 \mathrm{sec}$ whenever a reinforcer was scheduled. IBM compatible computers using MED State software were used to control experimental chambers.

\section{Training Procedure}

Animals were trained to discriminate phencyclidine $\mathrm{HCl}(2.5 \mathrm{mg} / \mathrm{kg})$ from saline $(0.9 \% \mathrm{NaCl})$ in a manner described by Cunningham and Appel (1987). Training injections were given intraperitoneally (i.p.), $15 \mathrm{~min}$ before daily (Monday to Friday) experimental sessions. During the training stage of an experiment, only the drug-appropriate lever was present (PCP or saline). Rats were randomly assigned to levers in order to control for lever bias. The order of stimulus (drug) presentation was also random with the restriction that neither drug was administered for more than three consecutive sessions. Lever pressing was initially maintained under a fixed-ratio (FR 1) schedule of reinforcement; as response rates stabilized, the ratio was raised gradually to FR 20.

\section{Discrimination Training}

After all rats were responding reliably under the FR 20 schedule, both levers were presented simultaneously. Responses on the incorrect lever were recorded but had no additional consequences. Training continued until an animal reached the criterion of at least $80 \%$ responding on the correct lever for seven consecutive sessions.

\section{Testing}

Rats were pretreated with either vehicle (control) or antagonist at either 60 or $90 \mathrm{~min}$ before behavioral testing; 45 or $75 \mathrm{~min}$ before PCP, as indicated in Table 1. Tests terminated as soon as 20 responses were completed on either lever, and were conducted under extinction conditions one to two times a week. Only rats maintaining accurate discrimination during intervening training sessions (a minimum of three sessions at $80 \%$ correct) continued to be tested.

Table 1. Effects of Six Drugs Given at the Times Indicated in Combination with PCP $(2.5 \mathrm{mg} / \mathrm{kg})$ to Rats Trained to Discriminate PCP from Saline

\begin{tabular}{llcccc}
\hline Drug & Doses (mg/kg) & $\mathbf{N}$ & $\begin{array}{c}\text { Time } \\
(\mathbf{m i n})\end{array}$ & $\begin{array}{c}\mathbf{A D}_{\mathbf{5 0}} \\
(\mathbf{m g} / \mathbf{k g})\end{array}$ & $\mathbf{9 5 \%} \mathbf{C I}$ \\
\hline LSD & $0.08,0.16,0.32$ & 16 & 60 & 0.19 & $0.04-0.31$ \\
DMT & $2,4,8$ & 16 & 60 & 7.57 & $4.22-9.80$ \\
LHM & $0.1,0.2,0.4$ & 16 & 60 & 0.22 & $0.06-0.85$ \\
DOM & $1,2,4$ & 16 & 90 & 1.37 & $0.87-2.15$ \\
Spiperone & $0.1,0.2,0.4$ & 11 & 90 & - & \\
Ritanserin & $2.5,5,10$ & 14 & 90 & - & \\
\hline
\end{tabular}




\section{Drugs}

As indicated in Table 1, the following compounds were tested in combination with the training drug [PCP; phencyclidine hydrochloride, $2.5 \mathrm{mg} / \mathrm{kg}]$ : LSD, d-lysergic acid diethylamide bitartrate; DMT, N,N-dimethyltryptamine oxalate; or LHM, lisuride hydrogen maleate; DOM, $\pm 2,5$ dimethoxy-4-methyl-amphetamine sulfate; spiperone HCL; and ritanserin. All drugs were dissolved in $0.9 \%$ saline and were given i.p. in a volume of $1 \mathrm{ml} / \mathrm{kg}$ except ritanserin which was first dissolved in a few drops of $3 \mathrm{M}$ glacial acetic acid. LSD was obtained from the National Institute on Drug Abuse (NIDA; Rockville, MD); all other compounds were purchased from Research Biochemicals, Inc. (Natick, MA).

\section{Data Analysis}

Antagonist Dose $\left(\mathrm{AD}_{50}\right)$ and $95 \%$ confidence intervals (CI) were determined in a manner described by Tallar- ida and Murray (1987). To be included in the analysis of the effects of each test drug, each animal had to make at least 10 responses on either lever following all doses of the respective antagonist (see Table 1). Complete antagonism was defined as less than $20 \%$ responding on PCP-appropriate lever. Responding between $20 \%$ and $49 \%$ on the PCP-lever was considered partial antagonism.

Rates of responding prior to completion of the first 20 responses on one lever were analyzed for each test drug using a repeated measures ANOVA. For significant comparisons $(p<.05)$, post hoc analyses were performed using the Bonferroni All Pairwise method of comparison.

\section{RESULTS}

Figure 1 shows that the PCP-saline discrimination was acquired in an average of 35 days. Once acquired, performance remained at criterion levels of accuracy $(\geqslant 80 \%)$ for the duration of the experiment.
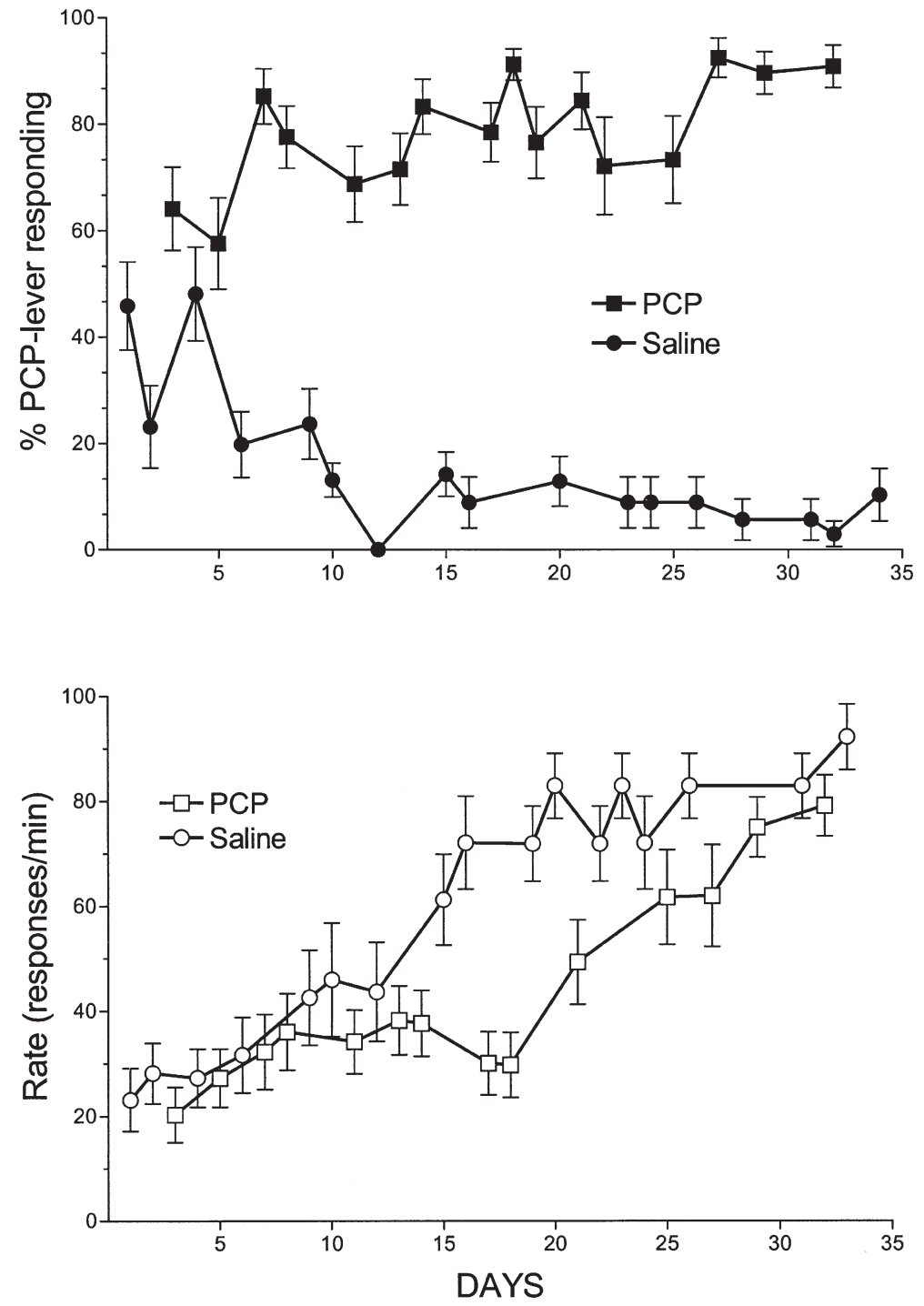

Figure 1. Acquisition of a discrimination between intraperitoneal injections of PCP $(2.5 \mathrm{mg} / \mathrm{kg})$ and saline, given 15 min prior to training in 16 rats. The top curve shows the average percent of responding on the drug-appropriate lever under each training condition (PCP or saline) and the bottom curve shows the average rate of responding between the onset of discrimination training until combination testing began. 
The results of combination tests with LSD and DOM are shown in Figure 2. Pre-treatment with LSD antagonized the PCP cue completely $(18 \%)$ with $\mathrm{AD}_{50}=0.19$ $\mathrm{mg} / \mathrm{kg}$. In addition, this antagonism occurred without any significant disruption of response rate $[\mathrm{F}(3,45)=$ $1.182, p=.327]$. Pretreatment with DOM also blocked the discriminative stimulus properties of PCP completely $\left(\mathrm{AD}_{50}=1.373\right)$. At the highest dose of DOM $(4.0 \mathrm{mg} / \mathrm{kg})$, PCP-lever responding was reduced to an average of $19.75 \%$. Rate of response was significantly different from control $[\mathrm{F}(3,45)=4.52, p<.01]$. Post hoc testing showed that the $4.0 \mathrm{mg} / \mathrm{kg}$ dose accounted for this difference.

Figure 3 shows the effects of LHM and DMT on the PCP-cue. LHM reduced PCP-lever responding, but only to $48 \%\left(\mathrm{AD}_{50}=0.22 \mathrm{mg} / \mathrm{kg}\right)$. Unlike LSD, $\mathrm{LHM}$ disrupted rate of responding significantly $[\mathrm{F}(3,45)=$ $10.00, p<.01]$. The highest dose $(0.4 \mathrm{mg} / \mathrm{kg})$ reduced the rate to nine responses/min; this was significantly different from all other doses tested.

DMT had an $\mathrm{AD}_{50}=7.57$ but, like LHM, failed to block the PCP discrimination completely ( $46 \%$ PCPlever responding). DMT also had significant effects on response rate $[\mathrm{F}(3,45)=3.975, p=.014]$. The highest dose lowered rate of response to 19.8 responses/min; an effect that was significantly lower than control.

The effects of spiperone and ritanserin on the PCPdiscrimination are shown in Figure 4. Spiperone failed to reduce PCP-lever responding below $80 \%$. However, the rate of responding was significantly reduced $[\mathrm{F}(3,30)=17.84, p<.01]$ and doses of 0.2 and $0.4 \mathrm{mg} / \mathrm{kg}$ had rate-depressing effects that were significantly lower than control. Ritanserin also failed to reduce PCP-lever responding and reduced the rate of response in a dose dependent manner $[\mathrm{F}(3,39)=5.68, p<.01]$;
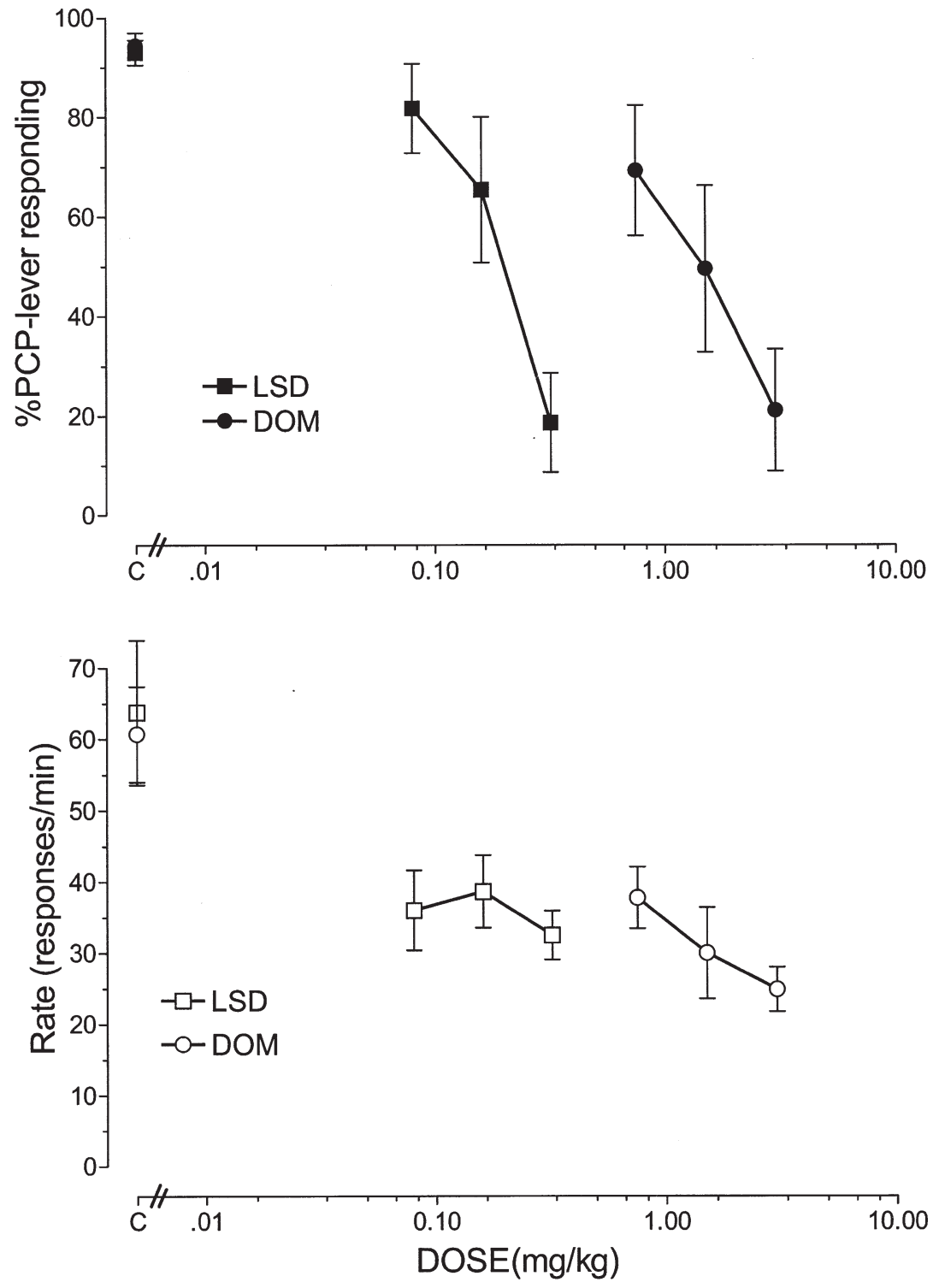

Figure 2. Results of combination tests with two indoleamine hallucinogens, LSD (given $60 \mathrm{~min}$ prior to testing; $45 \mathrm{~min}$ prior to $\mathrm{PCP}$ ) or $\mathrm{DOM}$ (given $90 \mathrm{~min}$ prior to testing; 75 min prior to $\mathrm{PCP}$ ), and $\mathrm{PCP}$, in 16 rats trained to discriminate PCP (2.5 $\mathrm{mg} / \mathrm{kg}$ ) from saline. Average effects of PCP in combination with vehicle controls on both percent responding on the drug appropriate lever (top figure) and rate of responding (bottom figure) are shown on the $y$ axis of each graph. 

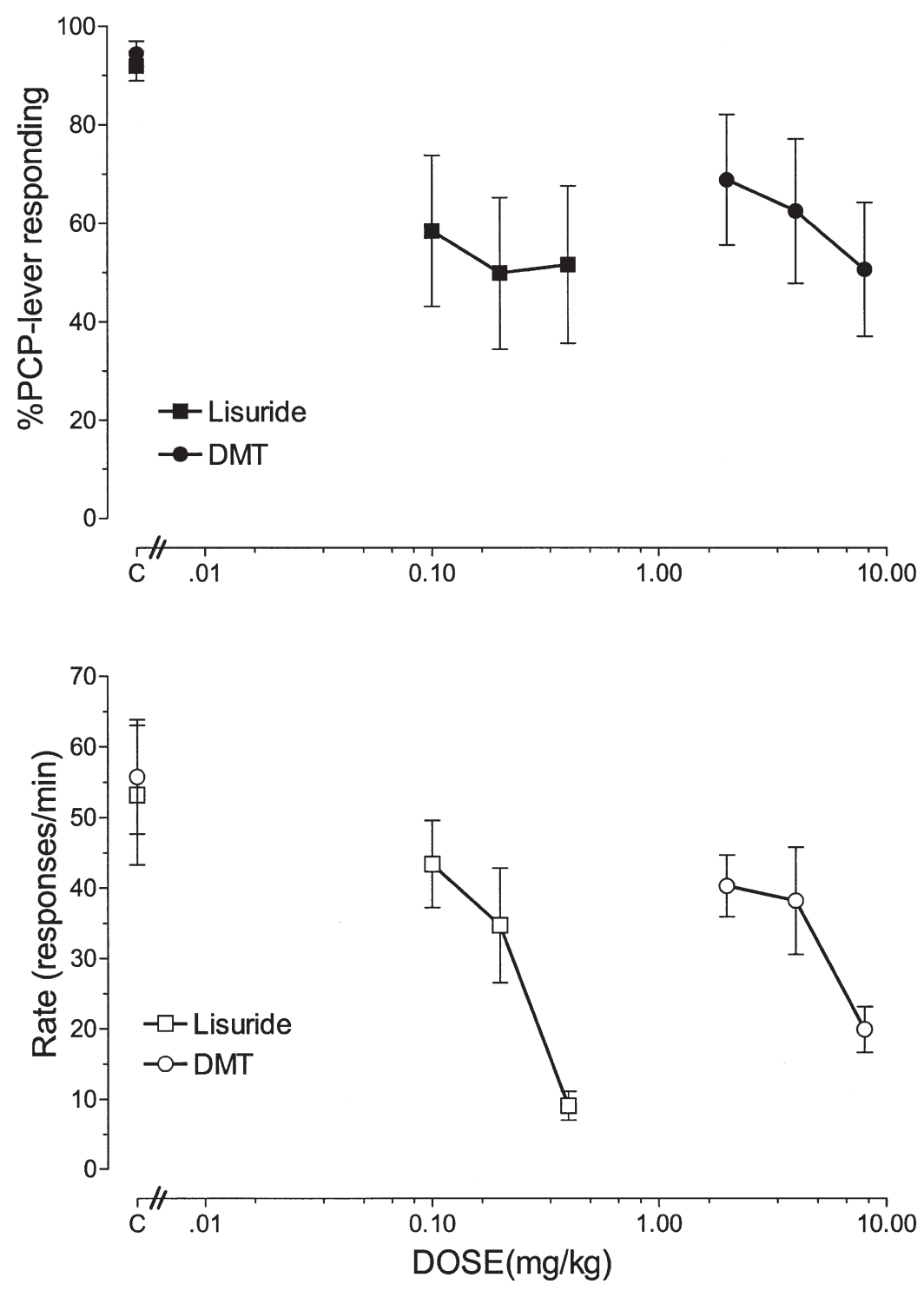

Figure 3. Results of combination tests with lisuride or DMT (both given $60 \mathrm{~min}$ prior to testing) and $\mathrm{PCP}$, in 16 rats trained to discriminate PCP from saline. Average effects of PCP in combination with vehicle controls on both percent responding on the drug appropriate lever (top figure) and rate of responding (bottom figure) are shown on the $y$ axis of each graph. the highest dose tested $(10 \mathrm{mg} / \mathrm{kg})$ had effects on rate that were significantly lower than control.

\section{DISCUSSION}

In the present study, LSD and DOM antagonized the PCP-discrimination completely; with LSD, this antagonism occurred without any concurrent disruption of response rate. LHM and DMT blocked the PCP cue partially; spiperone and ritanserin had no significant effects on ability to discriminate PCP from saline. In addition, LHM, DMT, spiperone, and ritanserin disrupted response rates significantly. These findings suggest that at least one behavioral effect of PCP (the PCP cue) can, like the neurotoxic effects of this NMDA antagonist (Farber et al. 1998), be attenuated by 5-HT2 agonists.

Many drugs with agonist properties at 5-HT2A re- ceptors also have agonist properties at 5-HT2C and other receptor subtypes; this is clearly the case with LSD (Marek and Aghajanian 1996), DOM (Glennon et al. 1992), and DMT (Smith et al. 1998). Therefore, it is difficult to attribute the behavioral or neurotoxic effects of these compounds exclusively to their actions at the 5-HT2A receptor. Lisuride may be a notable exception because its action at 5-HT2C receptors has been reported to be antagonistic (Burris et al. 1991). However, a recent study indicates that lisuride may act as an agonist at both 5-HT2A and 5-HT2C, as do other LSD-like drugs (Egan et al. 1998).

The present experiment found that lisuride blocked the discriminative stimulus properties of PCP partially. As mentioned previously, it is difficult to isolate the contribution of each 5-HT2 receptor subtype to this effect. Nonetheless, because spiperone and ritanserin failed to block the PCP-cue, it is likely that antagonist 

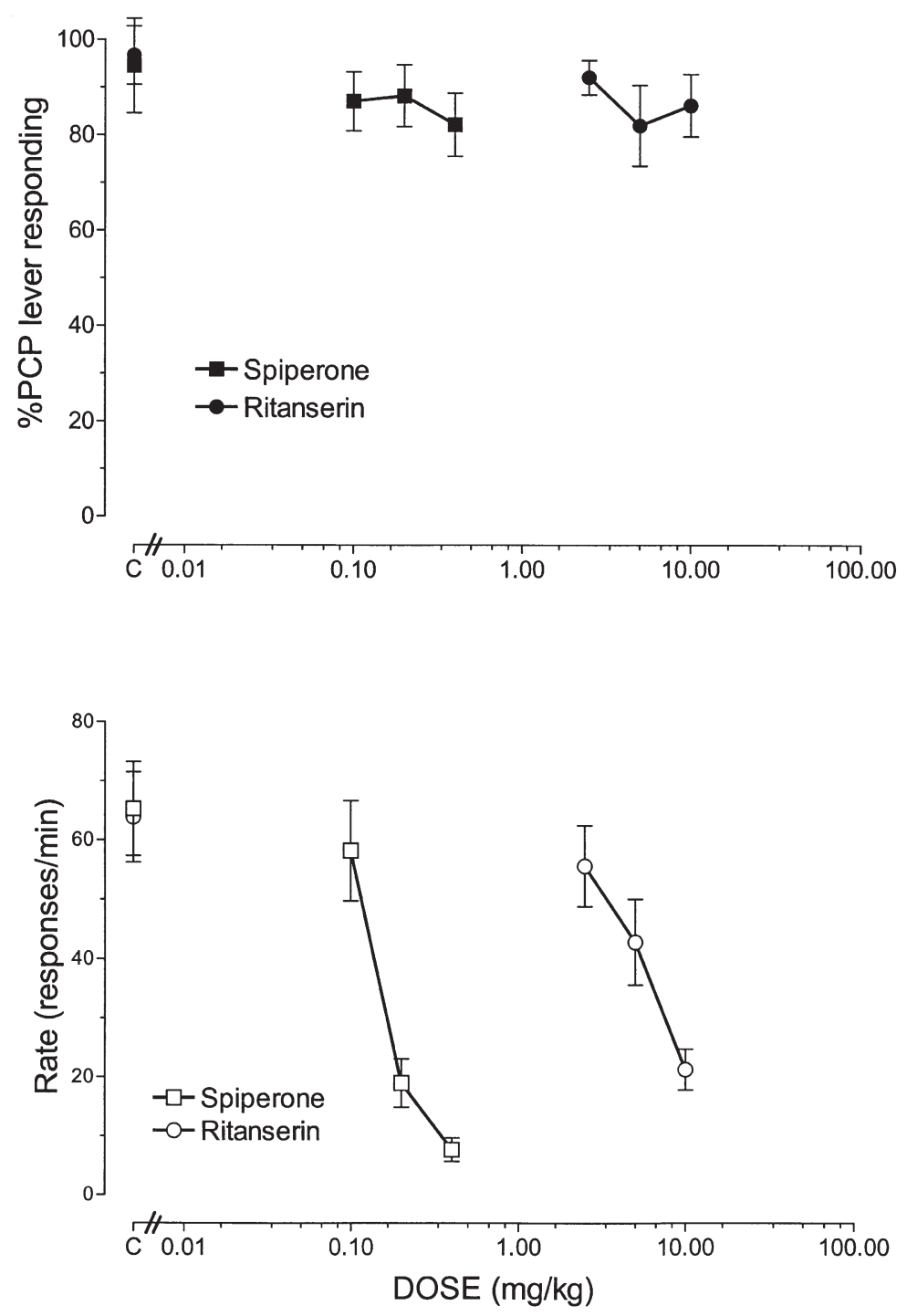

Figure 4. Results of combination tests with spiperone or (both given $90 \mathrm{~min}$ prior to testing; 45 min prior to $\mathrm{PCP}$ ) and $\mathrm{PCP}$, in 16 rats trained to discriminate PCP from saline. Average effects of PCP in combination with vehicle controls on both percent responding on the drug appropriate lever (top figure) and rate of responding (bottom figure) are shown on the y axis of each graph. The disruptive effects of these two drugs reduced the number of animals to 11 (spiperone) and 14 (ritanserin). Asterisks denote $p<.05$ (Bonferroni pairwise method of comparison). action at 5-HT2 receptors is less important than agonist action. In addition, the reduction in rate of responding following combination tests with LSD, DOM, DMT, and LHM suggests that something more than simple agonistic action of 5-HT2 receptors is involved in the attenuation of the PCP-cue.

In light of the findings of Farber et al. (1998), the results of this study suggest that the behavioral (discriminative stimulus) and neurotoxic effects of PCP are mediated by similar mechanisms, which might involve a circuit originally described by Olney and Farber (1995a, 1995b). These investigators suggested that NMDA receptor hypofunction is ultimately involved in the reinstatement of excitatory functions of neurons in the cingulate cortex. This disinhibition is thought to be a result of NMDA antagonists that decrease GABAergic input to otherwise excitatory cell bodies. Cholinergic neurons in the cingulate cortex are likely to be innervated by projections from basal forebrain and glutamatergic neu- rons in the anterior thalamus. With less inhibitory (GABA) influence on these excitatory neurons, an increase in excitatory transmission would be expected in regions such as the posterior cingulate and retrosplenial cortexes (Fix et al. 1995; Olney and Farber 1995b).

GABAergic interneurons in rat piriform cortex were shown to have significant concentrations of 5-HT2A receptors (Sheldon and Aghajanian 1990; Marek and Aghajanian 1996). Farber et al. (1998) proposed that activation of these receptors on GABAergic interneurons might restore inhibition of the NMDA receptor hypofunction-neurotoxicity circuit, thus preventing some of the damage caused by NMDA antagonists in the posterior cingulate and retrosplenial cortexes. Indeed, Farber et al. (1998) showed that pretreatment with hallucinogens such as LSD and DOM significantly reduced the neurotoxic effects of MK-801. Lisuride, a congener of LSD that is not known to produce hallucinations in humans (White and Appel 1982) was also able to block the 
neurotoxic effects of MK-801 (Farber et al. 1998). However, because lisuride has been reported to be a 5-HT2C agonist (Egan et al. 1998) and possibly a 5-HT2C antagonist, at least in the choroid plexus (Burris et al. 1991), determining the contribution of $5-\mathrm{HT} 2 \mathrm{C}$ in regards to the discriminative or neuroprotective properties of lisuride is, at best, difficult. Nonetheless, it appears that agonistic activity at the 5-HT2 receptors protects against the effects of NMDA antagonists-a result remarkably similar to that of the present experiment.

\section{ACKNOWLEDGMENTS}

This study was supported by USPHS Research Grant 5 R37 DA02543, from the National Institute on Drug Abuse.

\section{REFERENCES}

Appel JB, White FJ, Holohean AM (1982): Analyzing mechanism(s) of hallucinogenic drug action with drug discrimination procedures. Neurosci Biobehav Rev 6:529536

Balster RL (1991): Discriminative stimulus properties of phencyclidine and other NMDA antagonists. NIDA Res Monogr 116:163-180

Branchek T, Adham N, Macchi M, Kao HT, Hartig PR (1990): [3H]-DOB(4-bromo-2,5-dimethoxyphenylisopropylamine) and $[3 \mathrm{H}]$ ketanserin label two affinity states of the cloned human 5-hydroxytryptamine2 receptor. Mol Pharmacol 38:604-609

Burris KD, Breeding M, Sanders-Bush E (1991): (+)Lysergic acid diethylamide, but not its nonhallucinogenic congeners, is a potent serotonin 5HT1C receptor agonist. J Pharmacol Exp Ther 258:891-896

Cunningham KA, Appel JB (1987): Neuropharmacological reassessment of the discriminative stimulus properties of d-lysergic acid diethylamide (LSD). Psychopharmacology (Berl) 91:67-73

Egan CT, Herrick-Davis K, Miller K, Glennon RA, Teitler M (1998): Agonist activity of LSD and lisuride at cloned 5HT2A and 5HT2C receptors. Psychopharmacology (Berl.) 136:409-414

Farber NB, Hanslick J, Kirby C, McWilliams L, Olney JW (1998): Serotonergic agents that activate 5HT2A receptors prevent NMDA antagonist neurotoxicity. Neuropsychopharmacology 18:57-62

Fiorella D, Palumbo PA, Rabin RA, Winter JC (1995a): The time-dependent stimulus effects of R(-)-2,5-dimethoxy4- methamphetamine (DOM): Implications for druginduced stimulus control as a method for the study of hallucinogenic agents. Psychopharmacology (Berl) 119: 239-245

Fiorella D, Rabin RA, Winter JC (1995b): Role of 5-HT2A and 5-HT2C receptors in the stimulus effects of hallucinogenic drugs. II. Reassessment of LSD false positives. Psychopharmacology (Berl) 121:357-363
Fix AS, Wozniak DF, Truex LL, McEwen M, Miller JP, Olney JW (1995): Quantitative analysis of factors influencing neuronal necrosis induced by MK-801 in the rat posterior cingulate/retrosplenial cortex. Brain Res 696:194204

Glennon RA, Raghupathi R, Bartyzel P, Teitler M, Leonhardt $S$ (1992): Binding of phenylalkylamine derivatives at 5-HT1C and 5-HT2 serotonin receptors: Evidence for a lack of selectivity. J Med Chem 35:734-740

Glennon RA, Rosecrans JA, Young R (1983): Drug-induced discrimination: A description of the paradigm and a review of its specific application to the study of hallucinogenic agents. Med Res Rev 3:289-340

Grotta J, Clark W, Coull B, Pettigrew LC, Mackay B, Goldstein LB, Meissner I, Murphy D, LaRue L (1995): Safety and tolerability of the glutamate antagonist CGS 19755 (Selfotel) in patients with acute ischemic stroke. Results of a phase IIa randomized trial. Stroke 26:602-605

Javitt DC, Zukin SR (1991): Recent advances in the phencyclidine model of schizophrenia. Am J Psychiatry 148: 1301-1308

Koek W (1999): N-methyl-D-aspartate antagonists and drug discrimination. Pharmacol Biochem Behav 64(2):275-281

Koek W, Woods J (1988): Correlations between phencyclidine like-activity and N-methyl-d-aspartate antagonism: Behavioral evidence. In Domino E, Kamenka J (eds), Sigma and phencyclidine-like compounds as molecular probes in biology. Ann Arbor, NPP Books, pp 357-372

Koek W, Woods JH, Colpaert FC (1990): N-methyl-D-aspartate antagonism and phencyclidine-like activity: A drug discrimination analysis. J Pharmacol Exp Ther 253:1017-1025

Krebs-Thomson K, Paulus MP, Geyer MA (1998): Effects of hallucinogens on locomotor and investigatory activity and patterns: Influence of 5-HT2A and 5-HT2C receptors. Neuropsychopharmacology 18:339-351

Kristensen JD, Svensson B, Gordh T Jr (1992): The NMDAreceptor antagonist $\mathrm{CPP}$ abolishes neurogenic 'wind-up pain' after intrathecal administration in humans. Pain 51:249-253

Lodge D, Anis NA (1982): Effects of phencyclidine on excitatory amino acid activation of spinal interneurones in the cat. Eur J Pharmacol 77:203-204

Luby E, Gottlieb J, Cohen B, Rosenbaum G, Domino E (1962): Model psychosis and schizophrenia. Am J Psychiatry 119:61-67

Luby ED, Cohen BD, Rosenbaum G, Gottlieb JS, Kelly R (1959): Study of a new schizophrenic-like drug: Sernyl. Arch Neurol Psychiatry 81:363-369

Marek GJ, Aghajanian GK (1996): LSD and the phenethylamine hallucinogen DOI are potent partial agonists at 5-HT2A receptors on interneurons in rat piriform cortex. J Pharmacol Exp Ther 278:1373-1382

Olney JW, Farber NB (1995a): Glutamate receptor dysfunction and schizophrenia. Arch Gen Psychiatry 52:9981007

Olney JW, Farber NB (1995b): NMDA antagonists as neurotherapeutic drugs, psychotogens, neurotoxins, and research tools for studying schizophrenia. Neuropsychopharmacology 13:335-345

Olney JW, Labruyere J, Price MT (1989): Pathological 
changes induced in cerebrocortical neurons by phencyclidine and related drugs. Science 244:1360-1362

Olney JW, Labruyere J, Wang G, Wozniak DF, Price MT, Sesma MA (1991): NMDA antagonist neurotoxicity: Mechanism and prevention. Science 254:1515-1518

Sheldon PW, Aghajanian GK (1990): Serotonin (5-HT) induces IPSPs in pyramidal layer cells of rat piriform cortex: Evidence for the involvement of a 5-HT2-activated interneuron. Brain Res 506:62-69
Smith RL, Canton H, Barrett RJ, Sanders-Bush E (1998): Agonist properties of $\mathrm{N}, \mathrm{N}$-dimethyltryptamine at serotonin 5-HT2A and 5- HT2C receptors. Pharmacol Biochem Behav 61:323-330

Tallarida R, Murray R (1987): Manual of pharmacological calculations with computers. New York, Springer-Verlag

White FJ, Appel JB (1982): Lysergic acid diethylamide (LSD) and lisuride: Differentiation of their neuropharmacological actions. Science 216:535-537 